Original Research Paper

\title{
Carbon Nanodots from Frying Oil as Catalyst for Photocatalytic Degradation of Methylene Blue Assisted Solar Light Irradiation
}

\author{
Mahardika Prasetya Aji, Pradita Ajeng Wiguna, \\ Siti Aisyah Suciningtyas, Susanto, Nita Rosita and Sulhadi \\ Department of Physics, Universitas Negeri Semarang, Semarang, Indonesia
}

\author{
Article history \\ Received: 18-02-2016 \\ Revised: $15-04-2016$ \\ Accepted: 18-04-2016 \\ Corresponding Author: \\ Mahardika Prasetya Aji \\ Department of Physics, \\ Universitas Negeri Semarang, \\ Semarang, Indonesia \\ Email: mahardika190@gmail.com
}

\begin{abstract}
Carbon nanodots (C-Dots) of frying oil could be a photocatalyst for the degradation of methylene blue solution with assisted solar light irradiation. C-Dots of frying oil were resulted from the heating process at $\mathrm{T}=300^{\circ} \mathrm{C}$ for $2 \mathrm{~h}$. C-Dots of frying oil were used as a catalyst in methylene blue solution with variations the number of $\mathrm{C}$-Dots and the time of solar light irradiation. The results of photocatalytic process show the degradation of concentration from methylene blue solution. It was observed from the color change of the solution and the absorbance intensity decreases with increasing time of photocatalytic process. FTIR spectra showed that the hydroxyl functional group -OH changes and more widened at wavenumber 3468 $\mathrm{cm}^{-1}$ because the result of photocatytic process of methylene blue solution is water $\left(\mathrm{H}_{2} \mathrm{O}\right)$ and carbon dioxide $\left(\mathrm{CO}_{2}\right)$. Meanwhile, the intensity of the alkene functional group $\mathrm{C}=\mathrm{N}$ at wavenumber 1650 $\mathrm{cm}^{-1}$ decreased during the photocatalytic process. These results indicate that C-Dots of frying oil have an excellent potential to be developed as a photocatalyst materials.
\end{abstract}

Keywords: Carbon Nanodots, Photocatalyst and Methylene Blue

\section{Introduction}

Carbon nanodots (C-Dots) is the new material in a group of carbon nanomaterials which have the properties of fluorescence, low solubility in water and nontoxic. Currently, C-Dots becomes an attraction because it has a very large potential for application of photocatalysis, bioimaging and optoelectronic (Li et al., 2012). C-Dots can be produced simply through the process of hydrothermal with various types of sources of carbon such as citric acid, soy milk, orange juice, ginger, food waste, waste paper etc (Rahmayanti et al., 2015; Zhu et al., 2012; Sahu et al., 2012; Li et al., 2014; Park et al., 2014; Wei et al., 2014). The process of hydrothermal cause carbon chains suffered the polymerization processes and forming particle C-Dots. C-Dots also found in frying oils that have undergone the heating process. The bond of carbon chains that are abundant on the frying oil is easily broken as a result of the heating process and suffered the reorganization of carbon chains to form a particle C-Dots (Aji et al., 2015).

$\mathrm{C}$-Dots of frying oil have the potential application as photocatalyst materials because the material has a lower density than water, so C-Dots have a role as a catalyst that can effectively absorb photons from UV light or solar light irradiation. The C-Dots density from frying oil is lower than photocatalyst materials that has been commonly used for the degradation of methylene blue such as titanium dioxide $\left(\mathrm{TiO}_{2}\right)$. At the time of photocatalytic processes complete, the next process is $\mathrm{TiO}_{2}$ particles separated from the treated water. The separation processes of $\mathrm{TiO}_{2}$ particle which became one of the problems are quite complex. To be effectively used for photocatalytic, $\mathrm{TiO}_{2}$ particles require modification by way of immobilization of $\mathrm{TiO}_{2}$ particles on a polymer with a 
low density and transparent (Aliah et al., 2012; Subianto et al., 2013; Isnaeni et al., 2013; Nogueira and Jardim, 1993). In the present work, we report on the use of C-Dots from frying oil as catalyst for degradation of methylene blue under solar light irradiation. This works have an important benefits as a solution to the environmental problems of water pollutant degradation.

\section{Materials and Methods}

$\mathrm{C}$-Dots of frying oil were resulted from the heating process at a temperature $300^{\circ} \mathrm{C}$ for $2 \mathrm{~h}$ (Aji et al., 2015). C-Dots were used as catalyst in aqueous methylene blue test of $250 \mathrm{~mL}(100 \mathrm{ppm})$. The different number of $\mathrm{C}$-dots were used as catalyst for 10, 20, 30, 40, 50 and $60 \mathrm{~mL}$, as shown in Fig. 1. Meanwhile the test time of the photocatalytic process assisted solar light irradiation for 5, 10, 15, 20, 25 and $30 \mathrm{~h}$. The results of photocatalytic process were observed by measuring the absorbance spectrum with the UV-Vis- NIR Ocean Optics type USB 4000. In addition, measurement of the absorbance spectrum supported by device FTIR type Frontier FT-NIR/MIR Spectrometers L1280034 aims to observe the functional group which was present on the solution of the photocatalytic process results. The effectiveness of CDots from frying oil as a catalyst were observed from the absence elements of methylene blue in the water.

\section{Results and Discussion}

The results of photocatalytic in a solution of methylene blue with C-Dots from frying oil were shown in Fig. 2. The color change of methylene blue solution occurs during the photocatalytic process. It was caused by the different number of catalyst C-Dots that used. The number variation of catalyst $\mathrm{C}$-dots by the number of $10 \mathrm{~mL}$ are more effective for photocatalytic it shown by the color change of methylene blue solution that decrease significantly.
This is due to the layer of C-Dots on the top of methylene blue solution is thin so that photons from solar light can be effective as an energy source in the photocatalytic process. But the greater number of Cdots on methylene blue solution will form the thickness layer of C-Dots so that photons from the solar light are not effective for the photocatalytic process. Besides the number of catalyst C-Dots, the photocatalytic process in methylene blue solution was influenced by the length of time the solar light irradiation. The results of the time variation during the photocatalytic process showed that a solution of methylene blue degraded. These was indicated by the blue color of methylene blue solution is decreasingly fading away with the increasing time of the photocatalytic process. These results were supported by water absorbance spectrum from the results of photocatalytic process where the intensity of absorption of methylene blue particles increasingly decomposing.

The results above show that the photocatalytic process is strongly influenced by the number of catalyst C-Dots and the time during the photocatalytic process. A simple illustration that describe the process of photocatalytic was affected by layers thickness of catalyst C-Dots shown in Fig. 3.

The thickness of catalyst layers could be likened as C-Dots were layered. The photocatalytic process begins from photons of solar light irradiation with energy $h v$ crash into the surface of the catalyst C-Dots and produce pairs of electron $e^{-}$and hole $h^{+}$, with the equation: $C$ Dots $+h v \rightarrow C$ Dots $\left(\bar{e}+h^{+}\right)$. The pairs of $e^{-}$and $h^{+}$were always produced during solar light irradiation crash into the surface of the C-Dots. The pairs of $e$ - and $h+$ were the major agent in the process of photocatalytic. The thickness of the catalyst C-Dots layers made the pairs of $e^{-}$and $h^{+}$were generated on the surface of the C-Dots could not be directly crash into the contact area with a solution of methylene blue so that the photocatalytic process were observed slower.

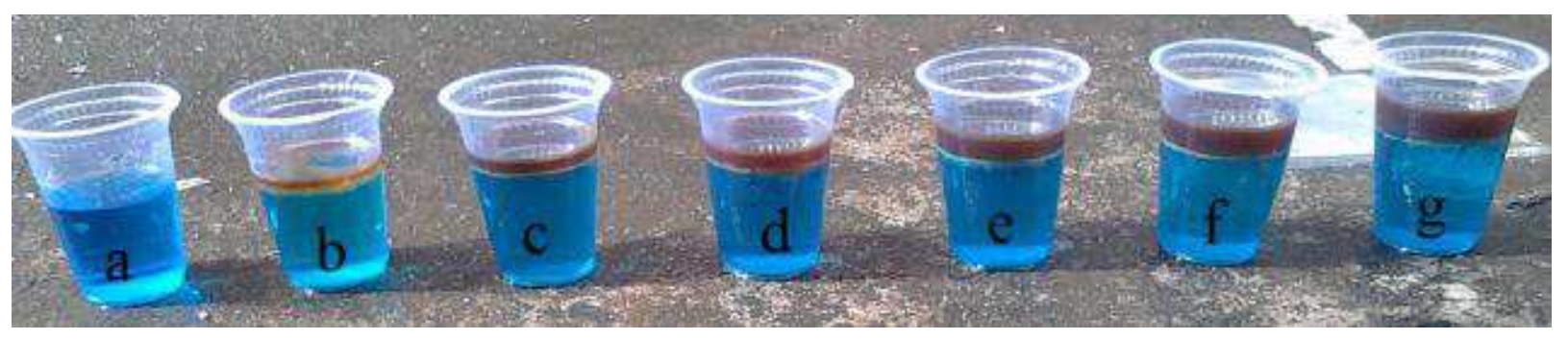

Fig. 1. (a). Methylene blue solution and methylene blue solution with catalyst C-Dots : (b). $10 \mathrm{~mL}$, (c). $20 \mathrm{~mL},(\mathrm{~d}) .30 \mathrm{~mL},(\mathrm{e}) .40$ $\mathrm{mL}$, (f). $50 \mathrm{~mL}$ and (g). $60 \mathrm{~mL}$ 


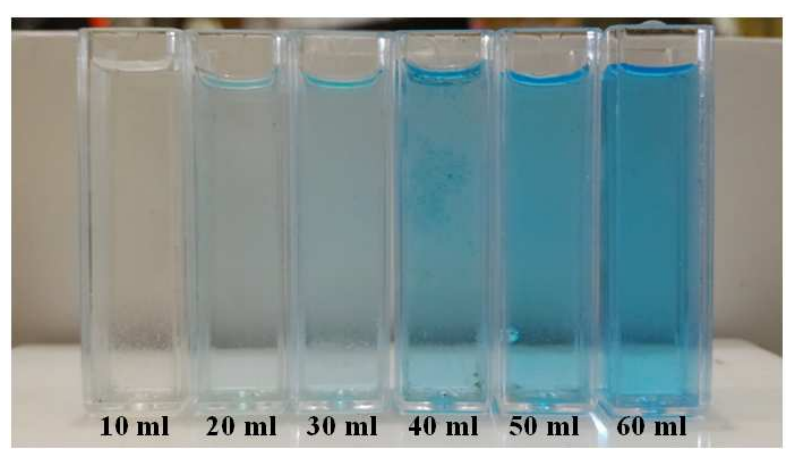

(a)

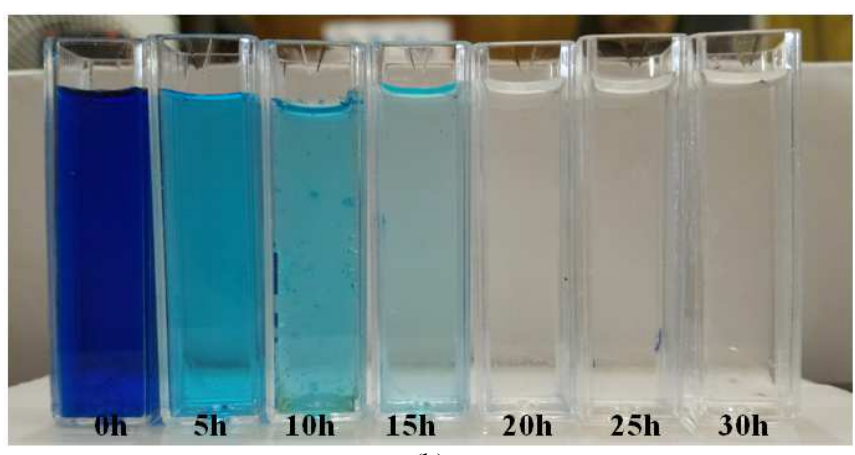

(b)

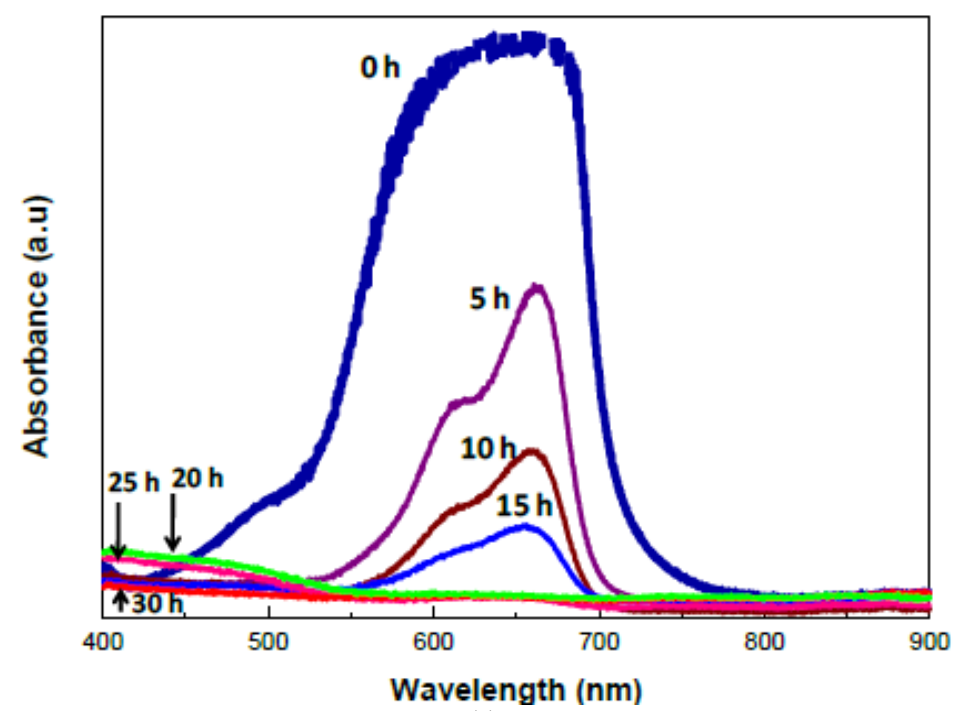

(c)

Fig. 2. Degradation methylene blue due to photocatalyst C-Dots with variation: (a). Volume and (b). Time process; and (c). Absorbance spectrum of methylene blue with time variation

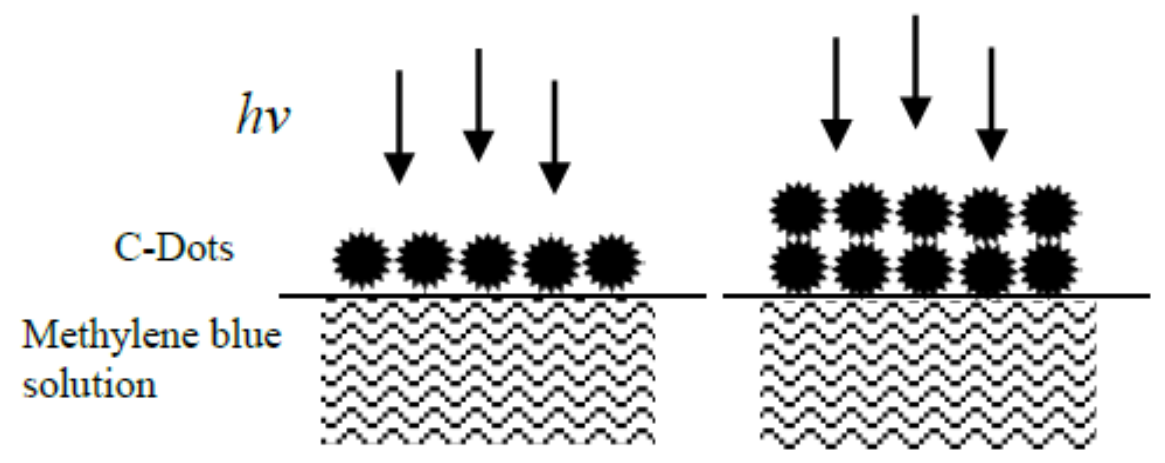

Fig. 3. Illustration of catalyst C-dots with different thicknesses of layers on the methylene blue solution

The decomposition of methylene blue solution on the photocatalytic process occurs by the diffusion mechanism. Change of the concentration $C$ of methylene blue was proportional to the diffusion current density $J$, as shown in Equation 1: $\frac{d C}{d t}=-\vec{\nabla} \bullet \vec{J}$

with $J=-D \vec{\nabla} C$ and $D$ is the diffusion constants. From the illustration in Fig. 3 was obtained assuming that 
the increase number of catalyst $C$-Dots causes the diffusion current density of $e^{-}$and $h^{+}$getting lower so that the rate of change in the concentration of methylene blue in water was getting smaller. This assumption was corresponds to the observations results, as shown in Fig. 2a. In addition, the photocatalytic process in a solution of methylene blue with catalyst $\mathrm{C}$-Dots were affected by exposure time from solar light irradiation, as shown in Fig. 2c. Degradation intensity of the absorption spectra in Fig. $2 \mathrm{c}$ represent a decreasing in the concentration. The relationship between the intensity of the absorption and concentration parameters could be estimated from the linear equation of Lambert-Beer, as shown in Equation 2 (Räty et al., 2003):

$$
\begin{aligned}
& I_{t}=I_{0} e^{-(\alpha \ell C)} \\
& \log \frac{I_{0}}{I_{t}}=\alpha \ell C=A
\end{aligned}
$$

with absorption coefficient $\alpha$, path length $l$, absorption $A, I_{0}$ and $I_{t}$ are the intensity of initial light and the intensity of transmission light. While the degradation mechanism of concentration from methylene blue solution during the photocatalytic process could be estimated from the model LangmuirHinshelwood where reaction rate $r$, was proportional to the change in concentration as shown in Equation 3 (Lotfy et al., 2012):

$$
\begin{aligned}
& r=-\frac{d C}{d t}=k C t \\
& C_{t}=C_{0} e^{-k t}
\end{aligned}
$$

with $k$ is the reaction rate constants and $t$ is the reaction time.

Methylene blue solution have the highest peak of the absorption spectral at wavenumber about $\sim 664$ $\mathrm{nm}$. By analyzing the maximum intensity at the peak of the highest absorption spectra, the degradation concentration of methylene blue solution from the photocatalytic process with catalyst C-Dots were shown in Fig. 4. The result showed that the ratio of decrease in concentration of methylene blue solution were observed sharply with estimate of reaction rate constants $k \sim 0.16$. These results indicate that $\mathrm{C}$-Dots from frying oil could be used as a catalyst for the degradation of methylene blue solution.

A simple scheme that describes the process of photocatalytic C-Dots in the methylene blue solution was shown in Fig. 5. The photocatalyst process was identical to the process of photosynthesis in plants.
Both of these processes use energy from the solar light irradiation, but the difference lies on the substances produced. If the process of photosynthesis will be releasing $\mathrm{O}_{2}$ as one of the results of the reaction, while the photocatalytic process will be releasing $\mathrm{CO}_{2}$. The reduction and oxidation reactions continue to occur during irradiation beam of solar light so that the photocatalytic process continues during there was solar light irradiation.

The solar light as a source of photon hit on particles C-Dots. Photon will excite electrons from the particles which have low energy to higher energy. These electrons react with oxygen $\mathrm{O}_{2}$ to form free radicals oxygen (superoxide) and produce hydrogen peroxide $\mathrm{H}_{2} \mathrm{O}_{2}$. This process corresponding with the equation $2 e^{-}+\mathrm{O}_{2}+\mathrm{H}_{2} \mathrm{O}$ $\rightarrow \mathrm{H}_{2} \mathrm{O}_{2}$. In addition, the other processes produce hydroxyl radicals (OH-) from the reaction: $h++\mathrm{H}_{2} \mathrm{O} \rightarrow$ $\mathrm{OH}-$ and $\mathrm{H}_{2} \mathrm{O}_{2}+e^{-} \rightarrow \mathrm{OH}^{-}+\mathrm{OH}$. These free radicals have a quite high potential to oxidize the organic substances thus produced hydrogen dioxide $\mathrm{H}_{2} \mathrm{O}$ and carbon dioxide $\mathrm{CO}_{2}$ gas (Aliah et al., 2012). The reduction and oxidation reactions which cause the degradation of methylene blue intensity due to the catalyst C-Dots. In the photocatalytic process, methylene blue solution will decomposes into water, acid and carbon dioxide gases. In the Fig. 6 was shown the reaction that occurs in the process of photocatalytic methylene blue with oxygen. Catalyst C-Dots have a role as a medium that produces free radicals such as superoxide and hydroxyl radicals. These elements which have a role in the decomposition process of methylene blue solution with the short relatively photocatalytic process.

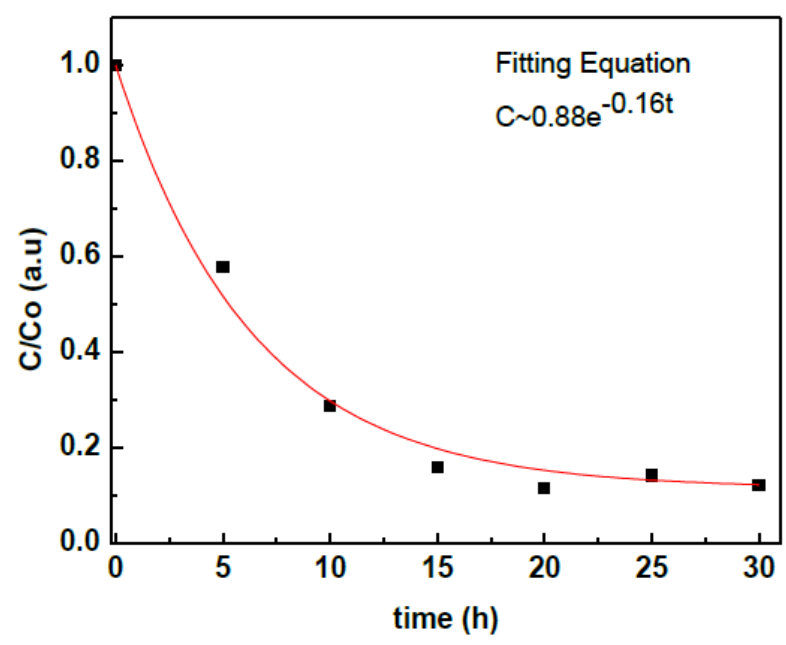

Fig. 4. Decreasing in concentration ratio of methylene blue solution 


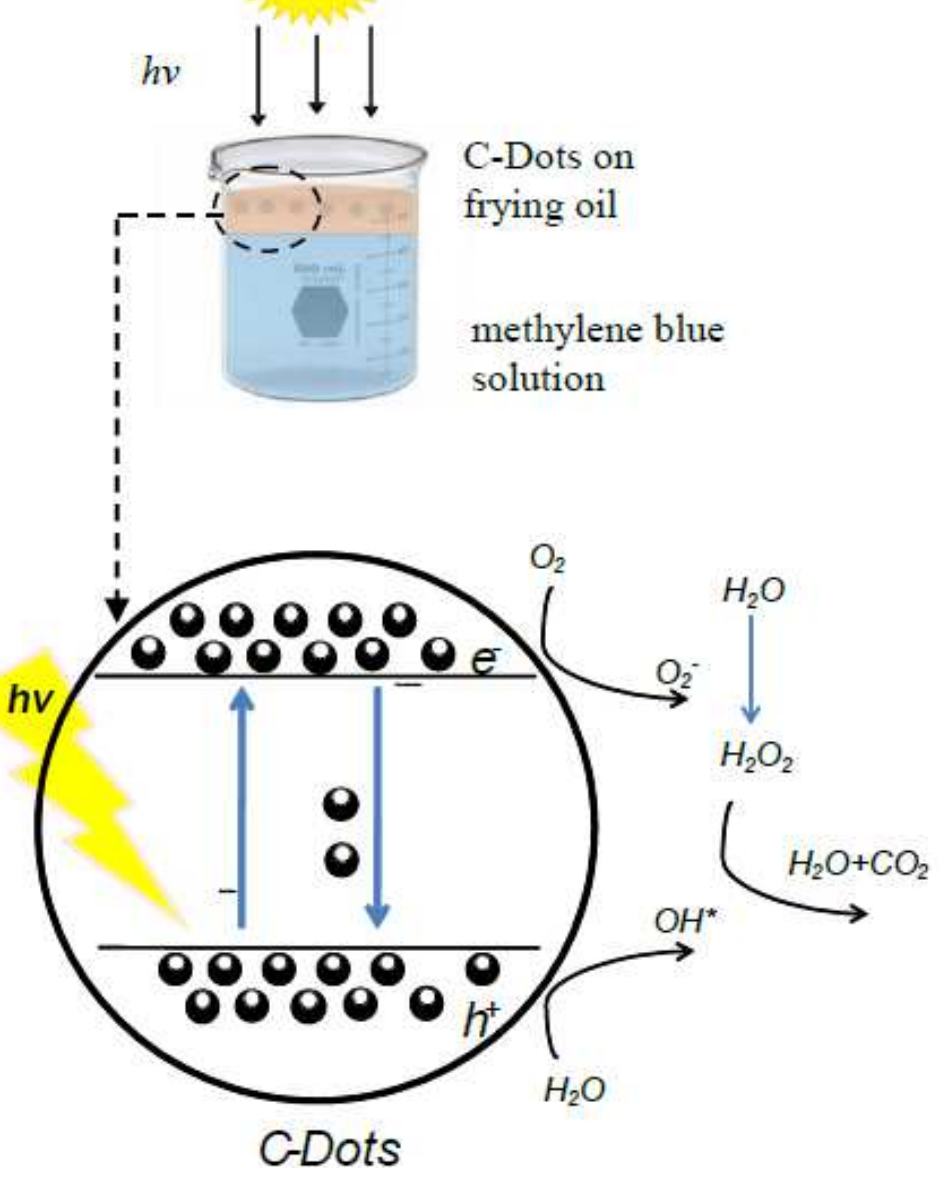

Fig. 5. Scheme of photocatalytic mechanism in C-Dots<smiles>CCCCCN(C)C1=Cc2c([N+](C)(C)[Cl+]Cl)ccc3nc(sc23)C=C1</smiles>

$\longrightarrow \mathrm{O}=\mathrm{C}=\mathrm{O}+\mathrm{H}-\mathrm{O}-\mathrm{H}+\stackrel{\mathrm{O}}{\mathrm{O}} \mathrm{N}-\mathrm{O}-\mathrm{H}+$<smiles></smiles>

Fig. 6. Decomposition of Methylene Blue 


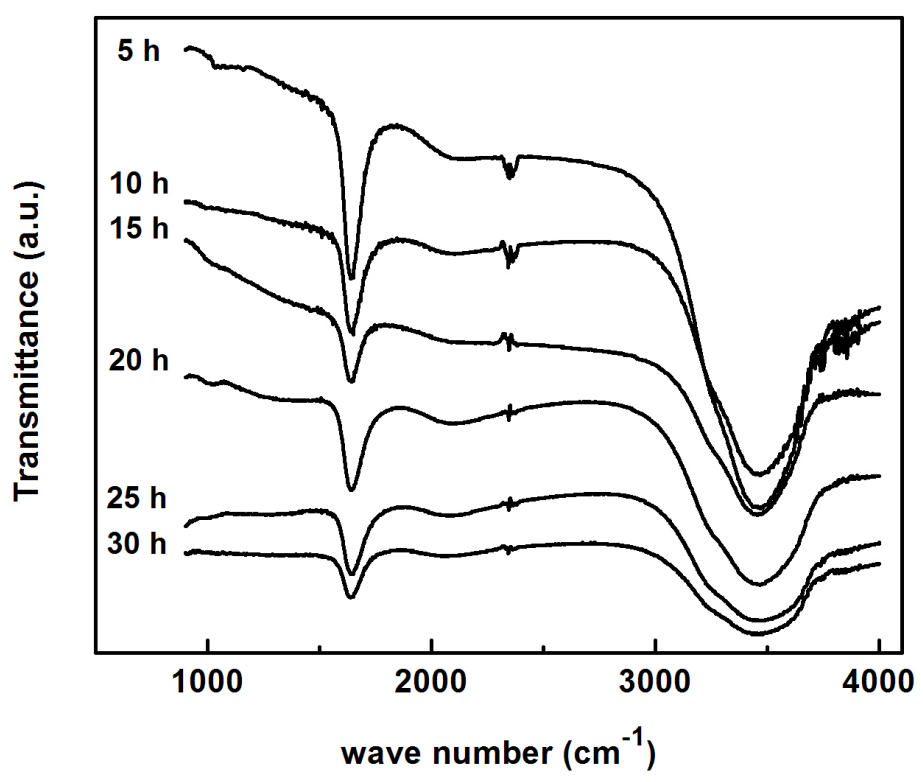

Fig. 7. The FTIR spectra of methylene blue solution of photocatalytic process results with time variations of solar light irradiation

Decomposition of methylene blue solution on the photocatalytic process as shown in Fig. 6 corresponds with the results of FTIR measurements, shown in Fig. 7. Photocatalytic process in a solution of methylene blue caused functional groups $-\mathrm{OH}$ more widened. This was due to the products of photocatalytic processes in the form of water. The longer time of the solar light irradiation made the concentration of free radicals $-\mathrm{OH}$ higher so that at wavenumber $3468 \mathrm{~cm}^{-1}$ was more widened. This condition caused acid levels decreased or increased levels of weat in solution. At the wavenumber of $1650 \mathrm{~cm}^{-1}$, the intensity of the alkene functional group $\mathrm{C}=\mathrm{N}$ decreases with increasing the length time of photocatalytic processes. However, the absorption peaks in the FTIR spectrum were observed identical with methylene blue solution. These observation corresponds with the results which obtained by many researchers on photocatalytic processes methylene blue with solar light irradiation. This condition was one of the characteristics of photocatalytic processes methylene blue (Aliah et al., 2012; Subianto et al., 2013).

\section{Conclusion}

C-dots made from frying oil could be used as a catalyst in the photocatalytic process of methylene blue solution. C-Dots could effectively decompose the methylene blue solution. Photocatalytic process with catalyst C-Dots from frying oil were influenced by the number of $\mathrm{C}$-dots and the duration of solar light irradiation. The number of catalyst C-Dots determining thickness of catalyst layer in the solution methylene blue. Photocatalytic process could effective with a layer of catalyst C-Dots were thin so that photons from solar light could be used as an energy source in photocatalytic process. Besides that, duration on the photocatalytic process in the solar light irradiation were greatly affects. The longer time of photocatalytic process made the higher decomposition of methylene blue solution with the reaction products such as water and carbon dioxide gas. Effectively of the decomposition process of methylene blue solution using C-Dots from frying oil become C-Dots have great potential to be developed as a catalyst material.

\section{Acknowledgement}

Authors are thankful to DRPM Kementrian Riset, Teknologi dan Pendidikan Tinggi, Indonesia for the financial support under the project research Grant Hibah Bersaing 2015-2016.

\section{Funding Information}

This research received specific grant from Grant Hibah Bersaing 2015-2016 DRPM Kementrian Riset, Teknologi dan Pendidikan Tinggi, Indonesia.

\section{Author's Contributions}

Mahardika Prasetya Aji: Participated in all experiments, coordinated the data-analysis and contributed to the writing of the manuscript.

Pradita Ajeng Wiguna: Participated in all experiments and contributed to the writing of the manuscript.

Siti Aisyah Suciningtyas: Participated in all experiments and coordinated the data-analysis. 
Susanto: Participated in all experiments.

Nita Rosita: Participated in all experiments.

Sulhadi: Designed the research plan and organized the study.

\section{Ethics}

This article is original and contains unpublished materials. The corresponding author confirms that all of the other authors have read and approved the manuscript.

\section{References}

Aji, M.P., P.A. Wiguna, Susanto, R. Wicaksono and Sulhadi, 2015. Identification of carbon dots in waste frying oil. Adv. Mat. Res., 1123: 402-404. DOI: 10.4028/www.scientific.net/AMR.1123.402

Aliah, H., M.P. Aji, S. Masturi, E. Sustini and M. Budiman et al., 2012. $\mathrm{TiO}_{2}$ nanoparticles-coated polypropylene copolymer as photocatalyst on methylene blue photodegradation under solar exposure. Am. J. Environ. Sci., 8: 280-290. DOI: 10.3844/ajessp.2012.280.290

Isnaeni, V.A., O. Arutanti, E. Sustini, H. Aliah and Khairurrijal et al., 2013. A novel system for producing photocatalytic titanium dioxide-coated fibers for decomposing organic pollutants in water. Environ. Prog. Sustain Energy, 32: 42-51. DOI: $10.1002 / \mathrm{ep} .10596$

Li, C.L., C.M. Ou, C.C. Huang, W.C. Wu and Y.P. Chen et al., 2014. Carbon dots prepared from ginger exhibiting efficient inhibition of human hepatocellular carcinoma cells. J. Mater. Chem. B, 2: 4564-4571. DOI: 10.1039/C4TB00216D

Li, H., Z. Kang, Y. Liu and S.T. Lee, 2012. Carbon nanodots: Synthesis, properties and application. J. Mater. Chem., 22: 24230-24253.

DOI: $10.1039 / \mathrm{C} 2 \mathrm{JM} 34690 \mathrm{G}$

Lotfy, H.R., J. Misihairabgwi and M.M. Mutwa, 2012. The preparation of activated carbon from agroforestry waste for wastewater treatment. Afr. J. Pure Applied Chem., 6: 149-156.

DOI: $10.5897 / A J P A C 12.019$
Nogueira, R.F.P. and W.F. Jardim, 1993. Photodegradation of methylene blue using solar light and semiconductor $\left(\mathrm{TiO}_{2}\right)$. J. Chem. Educ., 70: 861-862. DOI: 10.1021/ed070p861

Park, S.Y., H.U. Lee, E.S. Park, S.C. Lee and J.W. Lee et al., 2014. Photoluminescent green carbon nanodots from food-waste-derived sources: Large-scale synthesis, properties and biomedical applications. Applied Mater. Interfaces, 6: 3365-3370. DOI: $10.1021 / a m 500159 p$

Rahmayanti, H.D., Sulhadi and M.P. Aji, 2015. Synthesis of sulfur-doped carbon dots by simple heating method. Adv. Mat. Res., 1123: 233-236. DOI:10.4028/www.scientific.net/AMR.1123.233

Räty, J.A., K.E. Peiponen and T. Asakura, 2003. UVVisible Reflection Spectroscopy of Liquids. 1st Edn., Springer, New York, ISBN-10: 3540405828, pp: 224.

Sahu, S., B. Behera, T.K. Maiti and S. Mohapatra, 2012. Simple one-step synthesis of highly luminescent carbon dots from orange juice: Application as excellent bio-imaging agents. Chem. Commun., 48: 8835-8837. DOI: 10.1039/C2CC33796G

Subianto, H., B.W. Nuryadin, Khairurrijal, H. Mahfudz and N. Dananjaya et al., 2013. Distributed inner states $\mathrm{TiO}_{2}$-coated plastic fibers as photocatalysts for decomposing organic pollutants in water. J. Mater. Cycles Waste., 15: 210-217. DOI: $10.1007 / \mathrm{s} 10163-013-0116-\mathrm{y}$

Wei, J., J. Shen, X. Zhang, S. Guo and J. Pan et al., 2014. Simple one-step synthesis of water-soluble fluorescent carbon dots derived from paper ash. New J. Chem., 38: 906-909. DOI: $10.1039 / \mathrm{C} 3 \mathrm{NJ} 01325 \mathrm{~A}$

Zhu, C., J. Zhai and S. Dong, 2012. Bifunctional fluorescent carbon nanodots: Green synthesis via soy milk and application as metal-free electrocatalysts for oxygen reduction. Chem. Commun., 48: 9367-9369. DOI: $10.1039 / \mathrm{c} 2 \mathrm{cc} 33844 \mathrm{k}$ 